\title{
Isolated sporadic bilateral split hand malformation: a case report and review of the literature
}

\author{
Manjit Singh', Sukhminder Jit Singh Bajwa², Harsimarjit Kaur ${ }^{3}$, Ravinder Singh ${ }^{1}$ \\ ${ }^{1}$ Department of Orthopaedics, Gian Sagar Medical College and Hospital, Banur 140601, Punjab, India. \\ ${ }^{2}$ Department of Anaesthesiology and Intensive Care, Gian Sagar Medical College and Hospital, Banur 147001, Punjab, India. \\ ${ }^{3}$ Department of Anatomy, Govt. Medical College, Patiala 147001, Punjab, India.
}

Address for correspondence: Dr. Sukhminder Jit Singh Bajwa, Department of Anaesthesiology and Intensive Care, Gian Sagar Medical College and Hospital, Ram Nagar, Banur 140601, Punjab, India. E-mail: sukhminder_bajwa2001@yahoo.com

\begin{abstract}
Typical cleft hand is a rare disorder usually inherited in an autosomal-dominant manner. We report a case of bilateral typical cleft hand in a 6-year-old male. There was no positive family history of such presentation, and no systemic manifestations were associated with this entity. Preanesthetic evaluation revealed no systemic or airway challenges and parents were counseled for routine surgical and anesthetic risks. The hands underwent successful surgical reconstruction with no peri-operative complications. To the best of our knowledge, this is the first report of an operated case of an isolated, bilateral, and sporadic typical split hand malformation.
\end{abstract}

Key words:

Cleft hand, congenital anomalies, split hand malformation, syndactyly

\section{INTRODUCTION}

Surgical or medical co-morbidities of anesthetic or airway difficulties in patients with congenital anomalies need special consideration during corrective management, especially in the pediatric population..$^{[1-4]}$ Split hand malformation (SHM), characterized by median cleft in the hand, syndactyly, and/or a variable degree of underdevelopment of phalanges and metacarpals, is a rare entity. ${ }^{[5,6]}$ Associated co-morbidities can include sensori-neural hearing loss which can be challenging to identify when eliciting history during preanesthetic evaluation or during the anesthetic induction as such patients can be difficult to counsel. The literary evidence indicates the occurrence of multiple anomalies with SHM, but a literature search for isolated cleft hand

\begin{tabular}{|l|l|}
\hline \multicolumn{2}{|c|}{ Access this article online } \\
\hline Quick Response Code: & Website: \\
\hline & www.parjournal.net \\
\cline { 2 - 3 } & \\
\hline & \\
\hline
\end{tabular}

anomaly yielded only two results. ${ }^{[5,6]}$ The reported cases in the literature described only unilateral afflictions. We report a unique case of sporadic, isolated, bilateral SHM with syndactyly in both feet, which was successfully managed surgically and anesthetically with no untoward peri-operative incidents.

\section{CASE REPORT}

A 6-year-old male presented to the Orthopedic Outpatient Department with congenital abnormalities in both the hands and feet. He was the second of three children, born out of a nonconsanguineous marriage, delivered vaginally at full term with uneventful antenatal and perinatal course. Chief complaints of the parents pertained to the cosmetic concerns due to visible deformities. There were no skin lesions and no associated cleft lip/palate observed during a physical examination. The left hand was dominant, and there was no history of sensorineural deafness. On local examination, it was observed that there was complete obliteration of first web space in the right hand with the absence of the middle finger in both the hands. The right foot showed hypoplasia of the second toe with syndactyly between the third and fourth toes. The left foot had syndactyly between the third and fourth digits [Figure 1]. 
Radiographs were obtained which showed the absence of middle finger phalanges in both the hands. In the right hand, there was a variable absence of the third metacarpal while in the left hand the third metacarpal was almost fully developed. Two small transverse bones were visible on either side of the central ray in the left hand [Figure 2]. No bony deficiency was visible on radiographic examination of the feet. A hypoplastic second digit on the right foot was found to be devoid of the bony skeleton and the "great toe" consisted of first and second rays [Figure 3].

Preanesthetic evaluation did not reveal any systemic involvement, but the patient had a Mallampatti grade II with normal neck movements and body weight of $22 \mathrm{~kg}$. The patient was administered $5 \mathrm{~mL}$ syrup promethazine as a part of the premedication. In the operating theater, induction of anesthesia was achieved with oxygen in nitrous oxide, sevoflurane, propofol ( $2 \mathrm{mg} / \mathrm{kg}$ body weight), $50 \mu \mathrm{g}$ of fentanyl, and 2.5 vecuronium bromide for facilitation of endotracheal intubation using a cuffed endotracheal tube of $5.5 \mathrm{~mm}$ internal diameter. The first surgical procedure lasted for $2 \mathrm{~h}$, with extubation and the postoperative course uneventful. Diclofenac sodium was administered for postoperative pain relief. Surgery was performed in a staged manner with an interval of 3 weeks. The right hand underwent operation first: the central hypoplastic ray was excised, drill holes were made in the second and fourth metacarpals, and the 2 were held together using a 22-gauge stainless steel wire [Figure 4].

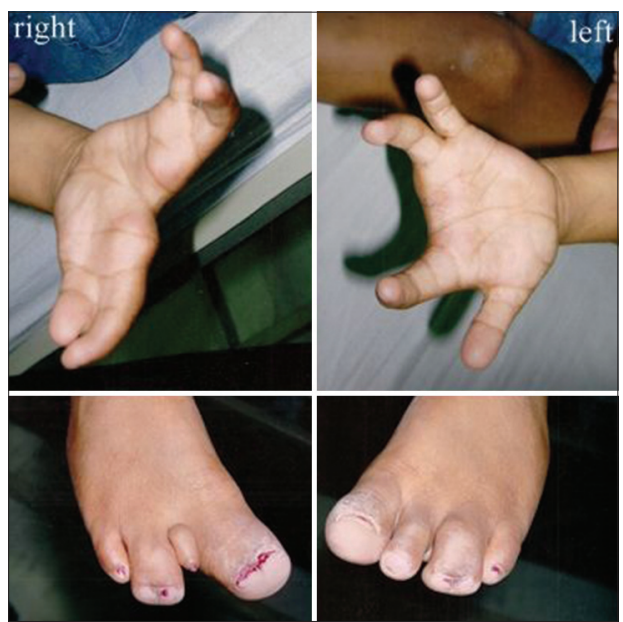

Figure 1: Preoperative clinical photographs of the hand and feet; right hand showing syndactyly between the thumb and index finger; the right foot showing syndactyly between the third and fourth rays and a hypoplastic second toe; the left foot showing syndactyly between the third and fourth toes

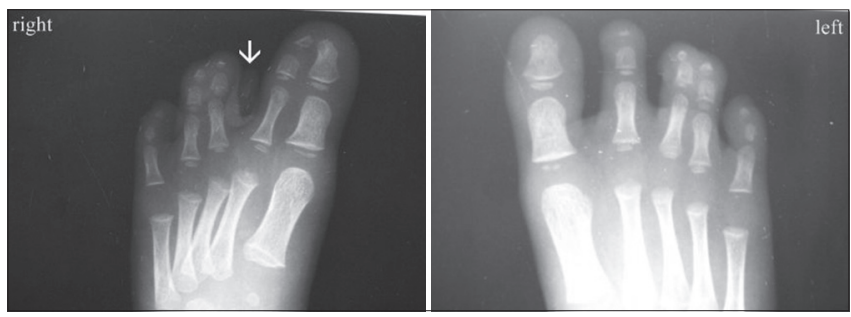

Figure 3: Radiographs of both feet; the hypoplastic toe in the right foot has no bony scaffold
A Z-shaped incision was made for syndactyly release. Adequate thumb abduction was achieved intraoperatively. In the left hand, central ray and transverse bony bridges were excised, and cleft closure was done. The diverging rays were held together employing a soft tissue sling functioning as the transverse metacarpal ligament. Postoperatively mobilization and strengthening exercises were instituted. Active abduction of the thumb on the right hand was especially encouraged. The patient was followed for 3 years, with a good functional and cosmetic outcome [Figure 5].

\section{DISCUSSION}

The literature is abundant with case reports where congenital abnormalities have always troubled surgeons and anesthesiologists whenever such patients present for surgical correction. However, in the present case, no such difficulties were encountered.

Split hand foot malformation (SHFM) involving the central rays of the extremities is usually inherited in an autosomal-dominant fashion. Various causative genes have been discovered, variable penetrance of which leads to the difference in severity of the manifestation. ${ }^{[7-9]}$ In the present case, a thorough pedigree analysis revealed a negative family history. Sporadic cases are usually encountered which show atypical cleft hands, which have more severe manifestations and are characterized by variable absence of middle, ring and index fingers. ${ }^{[10]}$

The cleft divides the hand in two separate radial and ulnar components. Sometimes a transverse bar of bone may be present at the base of the cleft, but multiple fragments were encountered in the present case. Syndactyly (most commonly thumb-index finger, as in the present case) and polydactyly are not uncommon associated findings.

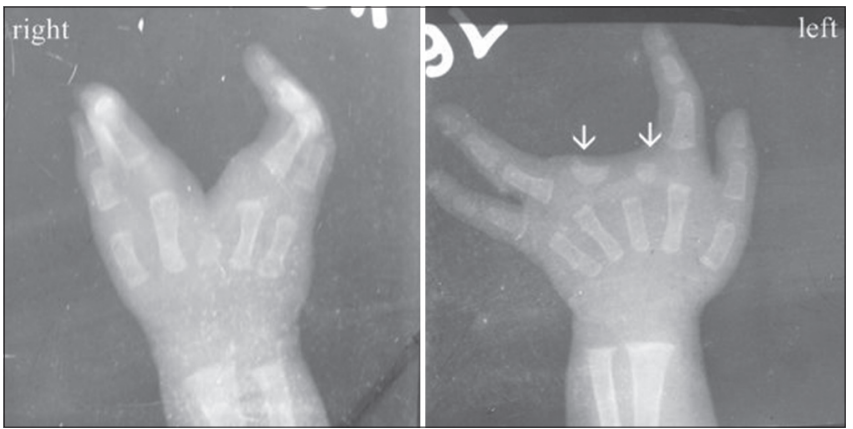

Figure 2: Preoperative radiographs of the hands; note the accessory transverse bony pieces in the cleft in the left hand (marked by arrows)
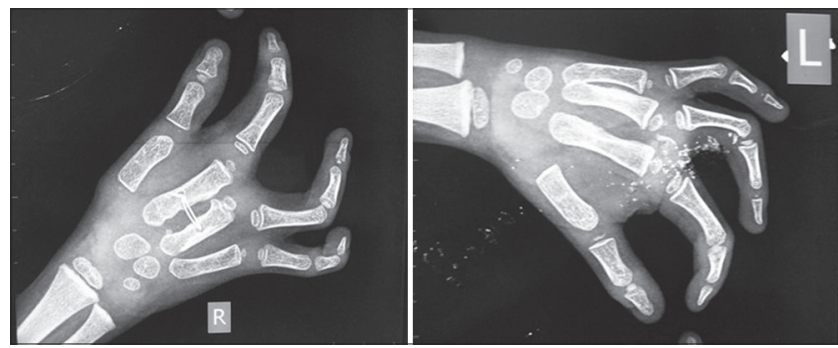

Figure 4: Postoperative radiographs of both hands 


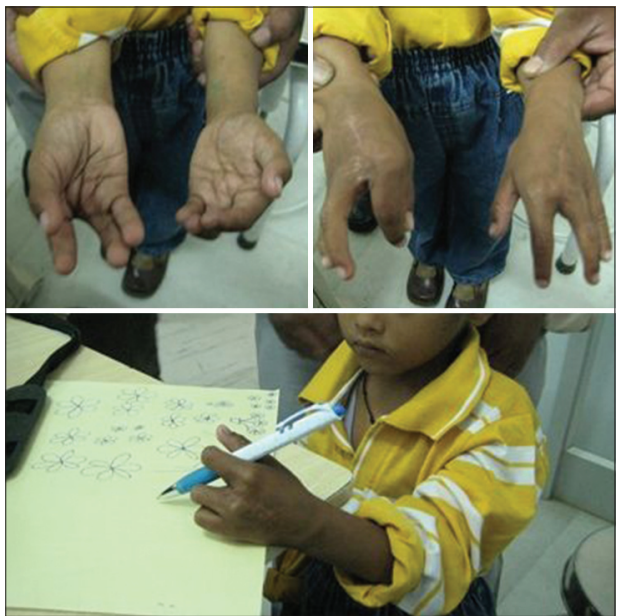

Figure 5: Functional and cosmetic outcome 1 year after surgery

Contraction of the first web space and limitation of thumb adduction is the main functional handicap encountered in such cases, based on which Manske and Halikis devised a severity classification. ${ }^{[11]}$

Numerous clinical associations of SHFM have been documented; cleft lip/palate seems to be a consistent accompanying manifestation. Such manifestations pose airway difficulties which can lead to a potential higher morbidity and mortality. The constellation of findings most commonly reported is ectrodactyly ectodermal dysplasia cleft lip/palate syndrome - ectrodactyly (SHFM), ectodermal dysplasia (coarse dry skin, glandular abnormalities), and cleft lip/palate. In the present case, a thorough search was made for associated systemic anomalies, but fortunately none were observed. Sporadic, isolated, bilateral typical cleft hand as reported above is indeed a rare entity.

Clinical diagnosis of SHFM is quite straightforward. Although there is no evidence in the literature regarding differences in outcome for patients presenting as syndromic cases or in isolation, the associated anomalies should be actively sought and treated accordingly. Radiographic examination of the bilateral hands, feet and skull should be carried out. In our opinion skin, biopsy is not a useful tool even if manifestations of ectodermal dysplasia are absent, as done by some authors. ${ }^{[6]}$ The outcome of skin biopsy findings do not guide decision-making.

Basic treatment goals are cleft closure for cosmetic reasons, syndactyly release, and restoration of the first web space for function. Mild cases are causing little functional impairment can be left untreated. Other issues that need attention in the treatment protocol are the cosmetic appearance of the limb and the overall psychology of the child. The ideal time for scheduling corrective surgery is at 18 months of age. The advantages of early surgery seem to be a correction of the deformity before the development of refined motor skills and the prevention of negative psychological effects on the child. In developing countries, this may be problematic due to the absence of a well-organized referral system. In the present case surgical intervention was undertaken at 6 years of age, albeit with a good outcome.

The cleft closure is achieved by excision of excess tissue including the third metacarpal and transverse bone bar if present. To hold the diverging metacarpals together, numerous techniques have been employed, such as heavy chromic catgut sutures or stainless steel wires, the latter done in the present case. ${ }^{[12]}$ For the restoration of the first web space, Snow and Littler advocated syndactyly release and utilization of skin from the palmar side. ${ }^{[13]}$ Barsky et al. employed a diamond-shaped flap from the cleft area itself to create a web space. ${ }^{[12]}$ In our case, the first web space was created surgically in the right hand by simple closure with a series of Z-plasties. The child may require rotational osteotomies of the metacarpals, especially the marginal ones, to achieve a useful pincer grasp if not restored adequately. ${ }^{[12]}$ No such procedure was done in this case as the patient and relatives were satisfied with the primary surgery outcome. Surgery for cleft foot is rarely required for hallux valgus correction and still rarer for cosmetic reasons. ${ }^{[14]}$

Typical and atypical cleft hand deformities occur with varying degrees of severity. Children learn to adapt from an early age and frequently develop remarkable functionality. If surgery is to be done, it should be planned carefully for each patient. The aim of surgery in these cases is mostly cosmetic. Any surgical procedure done should not jeopardize existing functions of the hand.

\section{REFERENCES}

I. Bajwa SJ, Kulshrestha A, Kaur J, Gupta S, Singh A, Parmar SS. The challenging aspects and successful anaesthetic management in a case of situs inversus totalis. Indian J Anaesth 2012;56:295-7.

2. Kulshrestha A, Bajwa SJ, Singh A, Kapoor V. Dexmedetomidine and fentanyl combination for procedural sedation in a case of Duchenne muscular dystrophy. Anesth Essays Res 201 I;5:224-6.

3. Bajwa SJ, Gupta S, Kaur J, Panda A, Bajwa SK, Singh A, Parmar SS, Prasad S. Anesthetic considerations and difficult airway management in a case of Noonan syndrome. Saudi J Anaesth 201 I;5:345-7.

4. Bajwa SJ, Bajwa SK, Singh A, Khan B, Parmar SS, Singh G, Kaur J. Anesthetic challenges and difficulties in the management of Treacher Collins syndrome. Anesth Essays Res 2011;5:111-3.

5. Padmavathy L, Lakshmana Rao L, Kanthimathi B, Adaikappan M, Ethirajan N. Unilateral cleft hand (lobster-claw deformity): a case report. J Chin Clin Med 2009;6:329-31.

6. Baba AN, Bhat YJ, Ahmed SM, Nazir A. Unilateral cleft hand with cleft foot. Int J Health Sci (Qassim) 2009;3:243-6.

7. Scherer SW, Poorkaj P, Allen T, Kim J, Geshuri D, Nunes M, Soder S, Stephens K, Pagon RA, Patton MA, Berg MA, Donlon T, Rivera H, Pfeiffer RA, Naritomi K, Hughes H, Genuardi M, Gurrieri F, Neri G, Lovrein E, Magenis E, Tsui LC, Evans JP. Fine mapping of the autosomal dominant split hand/ split foot locus on chromosome 7, band q21.3-q22.I. Am J Hum Genet 1994;55: I 2-20.

8. Gurrieri F, Prinos P, Tackels D, Kilpatrick MW, Allanson J, Genuardi M, Vuckov A, Nanni L, Sangiorgi E, Garofalo G, Nunes ME, Neri G, Schwartz C, Tsipouras P. A split hand-split foot (SHFM3) gene is located at 10q24-->25. Am J Med Genet 1996;62:427-36.

9. Boles RG, Pober BR, Gibson LH, Willis CR, McGrath J, Roberts DJ, Yang-Feng TL. Deletion of chromosome 2q24-q3। causes characteristic digital anomalies: case report and review. Am J Med Genet 1995;55:I55-60.

10. Jones NF, Kono M. Cleft hands with six metacarpals. J Hand Surg Am 2004;29:720-6.

II. Manske PR, Halikis MN. Surgical classification of central deficiency according to the thumb web. J Hand Surg Am 1995;20:687-97.

12. Barsky AJ. Cleft hand: classification, Incidence, and treatment. Review 
of the literature and Report of nineteen cases. J Bone Joint Surg Am 1964;46: 1707-20.

13. Snow JW, Littler JW. Surgical Treatment of Cleft Hand. Transactions of the Interenational Society of Plastic Reconstruction Surgeon, $4^{\text {th }}$ Congress. Rome: excerpta Medica Foundation; 1967. p. 888-93.

14. Abraham E, Waxman B, Shirali S, Durkin M. Congenital cleft-foot deformity treatment. J Pediatr Orthop 1999;19:404-10.
How to cite this article: Singh M, Bajwa SJ, Kaur H, Singh R. Isolated sporadic bilateral split hand malformation: a case report and review of the literature. Plast Aesthet Res 2014;1:114-7.

Source of Support: Nil, Conflict of Interest: None declared.

Received: 19-02-2014; Accepted: 29-07-2014 